\title{
Achieving Consciousness and Transformation in the Classroom: Race, Gender, Sexual Orientations and Social Justice
}

\author{
Manpreet Dhillon, Jerome Rabow, Vanessa Han, Saskia Maltz, Jennifer Moore \\ University of California, Los Angeles, USA \\ Email: m.dhillon@ucla.edu
}

Received 12 December 2014; accepted 19 February 2015; published 28 February 2015

Copyright (C) 2015 by authors and Scientific Research Publishing Inc.

This work is licensed under the Creative Commons Attribution International License (CC BY).

http://creativecommons.org/licenses/by/4.0/

c) (i) Open Access

\begin{abstract}
This paper examines the way in which the selected use of transformative pedagogy can affect student consciousness about race, gender, and sexual orientation. Students in an upper division honors class at a large research university were required to post six comments per week to an online class portal, related to readings, class discussions, videos, and presentations, for a class on the public education pedagogies. Our research examines these web posts where students are encourages and free to express their feelings and ideas. At the end of the semester, students were asked to utilize these posts in order to identify evidence of personal transformation. Both the original posts and students final papers were then coded using the typologies proposed by Bion in his work with psychoanalytic groups which classified statements by their "work-oriented" content or their fight/flight content (Bion, 1961). We found that students' final papers contained a larger percentage of work-oriented statements than their web-posts. This increase in self-examination and confrontation can be attributed to the transformation of identities. We argue that the work of Mezirow (1994) and Bion (1961) present useful ways of understanding transformation. We also suggest two major limitations of Mezirow's work are his neglect of multiple identities each of which can be involved in transformation and his failure to state explicitly that transformation, more often than not, involves action related to social justice.
\end{abstract}

\section{Keywords}

Transformative Pedagogy, Identity Transformations, Consciousness, Social Justice 


\section{Introduction}

Transformative pedagogy (TP) has meant different things to different scholars. Inspired by the pioneering work of John Dewey (1986) and continuing with the contemporary scholarship of bell hooks (1994), Paulo Freire (1970), and Gary Howard (2006), research on Transformative Pedagogy has developed to the point that we now have meta-analyses (Cranton, 2002; Taylor, 1997, 2007). Though there is a lack of consensus about what Transformative Pedagogy is or is not, we believe that the essence is captured by Jack Mezirow's (2000) description of emancipatory knowledge. For Mezirow, transformation involves a process of increasing awareness and consciousness. This process relies on the free expression of "distortions, prejudices, stereotypes, social context, and lack of knowledge" and the acquisition of "emancipator knowledge" which derives from critical reflection and self-reflection (Cranton, 1994: p. 27). When this new knowledge and information directly challenges established beliefs and practices individuals frequently respond with resistance. Critical examination comes about when individuals are able to freely exchange opinions, ideas, and beliefs in an environment that supports self-examination and the exploration of alternative viewpoints. Transformative learning occurs when these alternative views and experiences prompt individuals to recognize their own limitations, biases, stereotypes, false beliefs, and are encouraged to form new understandings (Cranton, 2002: p. 64). Although it is difficult to determine exactly what leads to transformation, the outcome is much clearer. In the words of Mezirow, "Transformation refers to a non-reversible shift in a person's meaning perspective towards greater inclusiveness, discrimination, openness or permeability (to other ideas), flexibility, reflexiveness and autonomy.” (Mezirow, 1978, 1991, 2000).

The current paper focuses on the way in which undergraduate students engage in this two-step process that allows them to develop emancipatory knowledge resulting in the transformation of their racial and gender identities, and an outlook on sexual orientation differences. Previous work using the same teaching pedagogy found shifts in the assumptions that people of different ethnicities and races made about each other, an openness and appreciation of differences as well as a reduction in racial prejudice (Rabow \& Yeghanazar, 2009). That research did not document the processes by which transformation occurred and this paper sought to address that issue. While much of TP methodology focuses on transformation, it is often unclear as to what this transformation involves. For hooks (1994), transformation means social action and for Howard, it means identity transformation. In this paper, we examine both these outcomes employing their work on identity shifts (Helms, 1992; Howard, 2006).

Our basic hypothesis is that the freedom of expression of stereotypes, false knowledge and assumptions, biases, and prejudices within a supportive group of peers is a necessary step towards effecting self-awareness and consciousness. When students can be provided with an analytic framework that allows them to classify and examine their thoughts, feelings, and ideas it enhances the possible movement towards emancipatory knowledge and increased activity against racism, sexism, and homophobia.

\subsection{Transformative Pedagogy}

In this paper, we use a transformative pedagogical framework to demonstrate how consciousness around issues of race, gender, and sexual orientation can be increased through a two-step process. These steps are 1) being able to freely express ideas and feelings, including anger, frustration, affection, and admiration, and 2) self-examination of these expressions.

In order to understand if transformation occurs, we utilize Mezirow's (2000) transformative learning theory. For Mezirow, emancipatory knowledge is the ultimate goal of education. Emancipatory knowledge is a difficult and often painful process because of innate "distortions, prejudices, stereotypes, social context, and lack of knowledge" in our perspectives (Cranton, 1994: p. 27). According to Mezirow, the limitations that all humans have in their perspectives results from their unique experiences and are therefore limited. When new information challenges their current knowledge and beliefs, they "will resist contradictions to their beliefs and will deny discrepancies between new learning and previous knowledge” (Cranton, 2002: p. 64). Transformative learning falls under the category of emancipatory knowledge, which is a product of critical reflection and critical self-reflection. Critical reflection occurs when an individual cultivates beliefs and assumptions and assess the validity and underlying premises of those beliefs or assumptions in light of new experiences or knowledge (Cranton, 2002). The process of critical reflection, ultimately leading to transformative learning, comes about as a result of the following: "It helps to talk to others, exchanging opinions and ideas, receiving support and encouragement, and engaging in discourse where alternatives are seriously weight and evidence brought forth. Insight, intuition, 
emotion, relationships, and personality may also play roles” (Cranton, 2002: p. 65). Therefore, transformative learning comes about when an individual "critically examines this [unaccustomed] view, opens herself to alternatives, and consequently changes the way she sees things” (Cranton, 2002: p. 64).

\subsection{The Class}

In the spring quarter of 2011, thirty students were enrolled in an Honors course at a major public university. The class was titled "Dominants and Subordinates: The Social Psychology of Privilege and Oppression in Education," and was designed to introduce students to the inequalities perpetuated within the public education system. Instruction was guided by the belief that transformation might occur when students felt they could freely express their thoughts, feelings, and beliefs about the educational process, their own education, and their beliefs about fellow students.

\subsection{Class Activities}

Class activities can be categorized into 5 types: 1) reading and writing assignments 2) small group (five to six students) discussion focused on the integration and application of course materials (Rabow \& Yeghnazar, 2009) 3) in class videos 4) class exercises 5) and web posts (described below).

\subsection{Web Posts}

Students were required to react the activities above in six weekly web-posts that on the class' online forum. In these posts, students were encouraged to relate and apply their own personal feelings and experiences to class activities. Students regularly responded to each other's posts, often leading to online discussion. The online forum, limited to class members only, served as an arena in which students could present questions, explore issues, dispute each other, disclose beliefs and prejudices, and expose shortcomings in understanding and contributed to the systematic effort to examine prejudices ${ }^{1}$. This forum created a safer space for students to continue their conversations beyond the classroom as they were informed that instructors would not access this forum.

\subsection{Final Papers}

In addition to the weekly web posts, students were required to submit a final paper that incorporated an analysis of their own web posts. They examined these web posts according to one of two identity schemes that had been introduced in the class to describe racial, gender, sexual orientation identities. The models used were: Howard's (2006) outlined in, We Can't Teach What We Don't Know, and Helms's (1992) A Race is a Nice Thing to Have. Both present continuums of identity extending from minimal awareness of racism, sexism, and homophobia to active understanding of the "other" and possible social justice action. Models also describe the ways in which movement along the continuums may occur and are often fluid.

\section{Sample}

A total of 781 web posts were generated by students in response to 28 activities (see Appendix 1). From these 781 posts, we elected to examine the web posts that received the largest number of responses from students. The three most frequently responded to activities were the stereotype $(n=51)$, gender $(N=78)$, and the privilege activities $(n=65)$. These posts constituted almost $25 \%$ of all web posts. These activities in turn generated threads where students moved beyond the activity into their own experiences, feelings, and ideas related to the topic. We also elected to examine the posts of 10 students who were chosen for their representative identities and gender and sexual orientation. Six out of the ten students were female, and of the four male students, one identified himself as a homosexual. The self-reported racial identities were: Whites (3), Asian Americans (3), Middle Easterners (2), and Latinas (2). There were no African-American students registered in the class. The final sample for the 10 students consisted of 75 web posts with 1189 coded statements.

\section{Coding}

The coding employed in the study is based on the theoretical work of Bion (1961) and the development of a coding scheme by William F. Hill (1966) for classifying verbal interaction. Both authors employ the concept of

\footnotetext{
${ }^{1} \mathrm{~A}$ list of the 28 activities that students responded to in their web-posts is available from the author.
} 
"work" and "pre-work" as guides for understanding what helps people change. There are two types of pre-work statements neither of which is designed to understand the self, the other, or a topic. The first type is a conventional statement which consists of the ordinary and everyday social contact and the second type is an assertive statement which expresses the speaker's version of his or her truth about other individuals and the world. The following statements are examples of pre-work: "I think you bring up a really a great point for discussion. I agree with you when you say that not all white people are the same.” This speaker does not allow her classmates to understand the basis of her agreement and any possible differences that she may have with her classmate therefore it is coded as conventional. An example of assertive pre-work is "Asians shut up and follow the rules and don't cause trouble.” In this statement, a student expresses a stereotypical view that so many Americans have of Asian Americans.

What separates pre-work statements from work statements is the element of interpersonal risk which is absent from pre-work statements. In the work category, there are speculative and confrontive statements. In speculative statements, students question their current beliefs without taking responsibility for examining the basis for these beliefs or for change. Confrontive statements reveal a new understanding of a topic, a relationship, or the self that results from the interactions between students which may involve hearing the personal experiences of "others" that challenges previous beliefs. When the listener feels that the challenge is not an attack but an honest communication, he or she is able to engage with the issue and often can demonstrate change in behavior or attitude. Examples of the work statements taken from the web posts follow.

\subsection{Speculative}

Does anyone else feel this way as a woman? Honestly, these issues of sexism surpass racial divides and affect women everywhere and it is very hurtful. I hope that we can learn to be advocates against racism and sexism after taking this class and have the courage to stand up and tell people you are wrong.

In this web post, the student expresses her hope without committing herself to what she is planning to do.

\subsection{Confrontation}

I always wonder, what have I done to give off the image that I am not smart enough to get a PhD or to have a successful career? But as we did this exercise, I realized that it isn't me at all. I realized that I have repeatedly been a victim of sexism on unfounded grounds. That makes me furious.

In the example above, a student comes to understand sexism in a way she has never been able to comprehend before this exercise. This student recognizes how sexism manifests in her world and which leads her to stop blaming herself.

A second example of confrontation, this time with the self, is presented by a male member of the class.

I clearly remember a time when a group of guys were harassing a girl at my community college by making rude and vulgar comments. I'm ashamed to say that I did not speak up. When the guys left, she asked me why I did not stand up for her. I had no answer. I was mortified by the experience... Because of this class, I can now identify with the women in this class as well as the women who I watched being harassed. I do feel a responsibility. I want to do my part to ensure that women feel safe.

This student recognizes that he can engage in an action that transforms his outlook from a passive spectator of sexism to an active opponent.

\subsection{Coding Procedures}

The senior author of this paper was trained in Provo, Utah ${ }^{2}$, in his work with delinquents, by W. F. Hill. He trained Vanessa Han until she became proficient in coding. Manpreet Dhillon did an independent coding of the web posts which demonstrated 87\% agreement. Disagreements were resolved by Professor Rabow.

\section{Research Procedures}

As mentioned above, there were 28 class events that students responded to ${ }^{3}$. The range of responses was 5 (for a video) to 78 (for the gender exercise). The three events selected for analysis included the gender exercise, the

${ }^{2}$ See “The Provo Experiment in Delinquency Rehabilitation” by L.T. Empey and Jerome Rabow (1961).

${ }^{3} \mathrm{~A}$ list of these events and the number of web posts that were generated from a particular event is available from the author. 
privilege activity (65 posts), and the stereotype exercise (51 posts). Even though the latter did not have the most posts, it was chosen because it was a class activity that all students participated in ${ }^{4}$.

\section{Findings}

An analysis of the 75 web posts for the three class events, over ten weeks, resulted in 1189 total statements (time 1) while the final papers consisted of 2829 total statements (time 2). Figure 1 illustrates the percentage of work and pre-work statements for the two time periods and reveals that the total number of pre-work statements is 940 while the total number of work statements is 249. To test the significance of the findings, proportion $z$ tests were conducted. The proportion of statements coded as pre-work was $79 \%$ whereas work statements comprised $21 \%$ of the total coded statements from the web posts. This difference was significant, $p(z<-4.92)=0.0000004, p<$ 0.05. In the final papers (time 2), the total number of pre-work statements was 1531 and the total number of work statements was 1298 . The proportion of pre-work statements (54\%) was found to be significantly greater than the proportion of work statements (46\%) for the final papers (time 2$), p(z<-32.02)=0, p<0.05$.

A comparison of work orientated statements for time one (21\%) and the increase for time two (46\%) was also significant, $p(z>28.97)=0, p<0.05$. This finding supports the hypothesis that the amount of work statements will increase after there can be a free expression of feelings and emotions and stereotypes (time 1) and then a critical self-examination (time 2). A comparison of statements across time categories reveals that the proportion of statements categorized as "pre-work" decreased from 79\% to 54\%. This decrease was found to be significant, $p(z<-30.53)=0, p<0.05$.

Figure 2 compares the percentage of types of statements for times one and two. Examination reveals that the percent of confrontive statements in time two at $42 \%$ increased from $14 \%$ at time one. This increase was found to be significant, $p(z>51.15)=0, p<0.05$. Conventional, assertive, and speculative statements all diminished in time two.

Table 1 summarizes the self-perceived identity shifts for each of the ten students ${ }^{5}$. All students report shifts in these three major identities, except for the Asian American gay male. When we elected to examine the initial stages of identity, we found that all three identities have an average starting point between stage two and stage three, with sexual orientation identity having the highest average starting stage (2.7). We also calculated that the average shift in the three identities was highest in racial identity (3.2) and lowest in sexual orientation identity (1.9). This shift is noteworthy because it suggests that the requirement for movement between stages is probably unequal.

The average initial starting stage for sexual orientation identity also suggests that, at least for this small sample and at this elite public university, there are less pre-existing prejudicial beliefs against homophobia than racial and gender prejudicial beliefs. In looking at the shifts for males and females, for whites and non-whites, all groups evidenced movements towards autonomy. The sub-samples were too small to judge significance or draw comparisons.

\section{Conclusion}

These findings are based on 4018 statements taken from students' web posts and the commentary, interpretations, and clarifications exhibited within students' final papers. From our analyses, there was a significant shift from pre-work statements, at the beginning and during the class, to work statements at the end.

This paper argues that transformation of racial, gender, and sexual identities can occur through a process of free self-expression, self-examination, and confrontation. One of the major contributions suggested by our findings is that transformation can occur with more than one identity when transformative pedagogy within a group setting is employed. Mezirow has not addressed this idea in his ten step transformation (Mezirow, 2002). Students like others working within groups can avoid issues and problems (flight) and can disagree with the issues being presented by the instructors or fellow students (fight). Through Bion's (1961) original work stemming out of his psychoanalytic training and background, we show that "work" can be done in college classrooms without addressing intrapsychic dynamics.

\footnotetext{
${ }^{4} \mathrm{~A}$ full description of the exercises is available from the author.

${ }^{5}$ The stages have been numbered as the following: Howard and Helms' models, the stages are: 1) contact, 2) disintegration, 3) reintegration, 4) pseudo-independence, 5) immersion-emersion, and 6) autonomy; Helms' stages for people of color are: 1) conformity, 2) dissonance, 3) immersion, 4) emersion, 5) internalization, and 6) integrative awareness.
} 


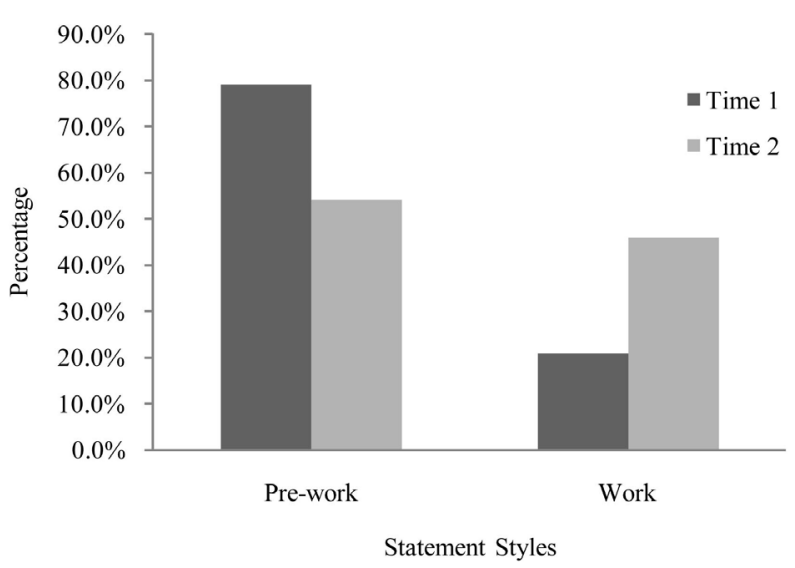

Figure 1. Illustrates the percentage of work and pre-work statements for the two time periods.

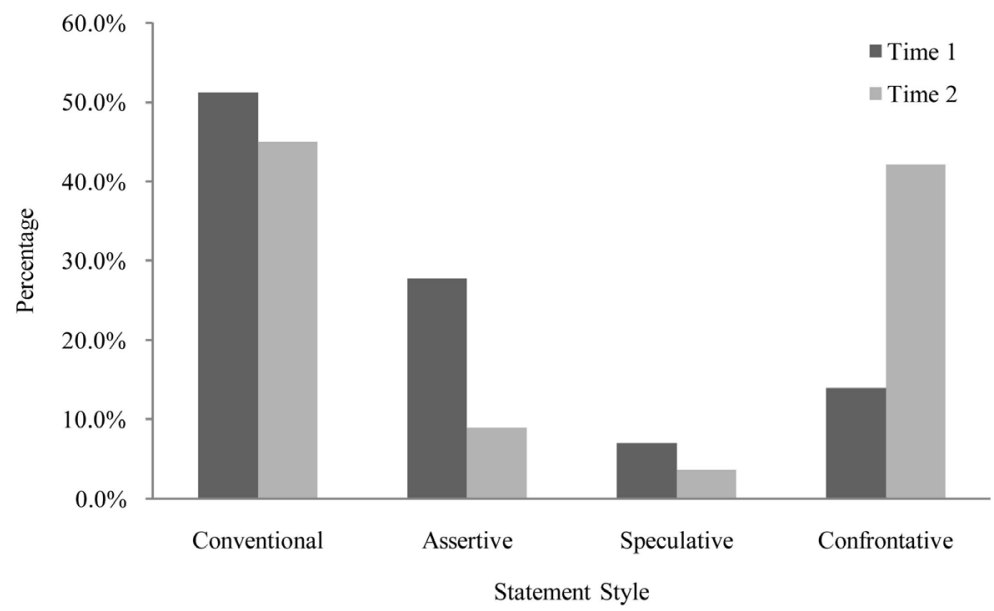

Figure 2. This figure demonstrates the comparison between the percentages of each type of statements found within time one and time two.

Table 1. Demonstrates the starting and ending identity shifts in race, gender, sexual orientation.

\begin{tabular}{|c|c|c|c|}
\hline \multicolumn{4}{|c|}{ Identity shifts for each student } \\
\hline Student & $\begin{array}{l}\text { Initial and final stages of } \\
\text { development in racial identity }\end{array}$ & $\begin{array}{l}\text { Initial and final stages of } \\
\text { development in gender identity }\end{array}$ & $\begin{array}{c}\text { Initial and final stages of } \\
\text { development in sexual orientation }\end{array}$ \\
\hline \#1: White male & $1 \rightarrow 6$ & $1 \rightarrow 6$ & $1 \rightarrow 6$ \\
\hline \#2: Latina female & $1 \rightarrow 5$ & $1 / 2 \rightarrow 3$ & $1 \rightarrow 3$ \\
\hline \#3: Asian male & $1 \rightarrow 5$ & $1 \rightarrow 6$ & $4 \rightarrow 5$ \\
\hline \#4: Middle Eastern male & $2 \rightarrow 6$ & $3 \rightarrow 5$ & $3 \rightarrow 5$ \\
\hline \#5: Middle Eastern female & $3 / 4 \rightarrow 5$ & $4 \rightarrow 6$ & $4 \rightarrow 5$ \\
\hline \#6: Asian female & $1 / 2 \rightarrow 3$ & $3 \rightarrow 4$ & $4 \rightarrow 5$ \\
\hline \#7: Latina female & $1 \rightarrow 5$ & $1 \rightarrow 5$ & $1 \rightarrow 4$ \\
\hline \#8: White female & $4 \rightarrow 5$ & $1 \rightarrow 5$ & $6 \rightarrow 6$ \\
\hline \#9: Asian homosexual male & $3 \rightarrow 5$ & $3 \rightarrow 5$ & $1 \rightarrow 1$ \\
\hline \#10: White female & $2 \rightarrow 5 / 6$ & $3 \rightarrow 5$ & $2 \rightarrow 6$ \\
\hline
\end{tabular}

We recognize that as a retrospective analysis, an independent measure of student identities prior to class might further deepen our understanding of movement change. While we have isolated two steps in the transformation process, it is likely that Mezirow's ten steps might be useful for analysis of these identity transformations. 
We note that Mezirow (2000) did not apply his analysis to the intersection of multiple identities and we believe that his analysis could be useful.

Finally, our findings suggest that student transformation can frequently involve students taking social action that addresses inequalities, an outcome that Mezirow does not address. Social action is much more explicit in the schemes proposed by Howard (2006) and Helms (1992) and is a key element of transformative pedagogy and which many of our students were able to apply in their understanding of race, gender, and homophobia. We provide examples of social action for the three identities in Appendix 2.

While this paper is limited to the examination of public statements and web posts, it does not include the private conversations between students after class in their other social encounters. Such examination might reveal the role of social connections in this transformation. This research highlights the value of having students continue conversations beyond the class in a class-created safer space (web-posts) that allows them to communicate a wide range of opinions and feelings without judgment by authority. Finally, the value of an analytic framework that allows students to retrospectively examine their contributions to the class forum and to use this framework to understand their own processes of transformation will likely endure beyond the immediacy of any single statement or conversation.

The limitations of this study are: 1) the small number of students used in the analysis which limits external validity; 2) the lack of representatives from major racial groups; 3) this being an honors class with perhaps greater privilege than other university students also limiting generalizability; and 4) the study ignores the way in which men and women might respond differently to challenges of their identities. Despite these limitations, we have demonstrated that identity transformation can occur in a classroom when there is an ongoing focus on self-examination in relation to objective materials (i.e. readings) as well as exercises that allow students to look at their own beliefs, prejudices, assumptions, stereotypes. We believe that transformative pedagogy teaching framework will allow students to engage in social action that is aimed at reducing inequalities in race, gender, and sexual orientation.

\section{References}

Bion, W. R. (1961). Experiences in Groups. London: Tavistock Publications. http://dx.doi.org/10.4324/9780203359075

Cranton, P. (1994). Understanding and Promoting Transformative Learning. San Francisco: Jossey-Bass Publishers.

Cranton, P. (2002). Teaching for Transformation. New Directions for Adult and Continuing Education, 2002, 63-72. http://dx.doi.org/10.1002/ace.50

Dewey, J. (1986). Experience and Education. The Educational Forum, 50, 241-252. http://dx.doi.org/10.1080/00131728609335764

Empey, L T., \& Rabow, J. (1961). The Provo Experiment in Delinquency Rehabilitation. American Sociological Review, 26, 679-695. http://dx.doi.org/10.2307/2090198

Freire, P. (1970). Pedagogy of the Oppressed. New York: Seabury Press.

Helms, J. E. (1992). A Race Is a Nice Thing to Have: A Guide to Being a White Person or Understanding the White Persons in Your Life. Arlington, VA: Content Communications.

Hill, W. F. (1966). The Hill Interaction Matrix. Los Angeles: University of Southern California.

hooks, b. (1994). Teaching to Transgress. New York, NY: Routledge.

Howard, G. (2006). We Can't Teach What We Don't Know. New York: Teacher's College Press.

Mezirow, J. (1991). Transformative Dimensions of Adult Learning. San Francisco: Jossey-Bass Publishers.

Mezirow, J. (2000). Learning to Think Like an Adult: Core Concepts of Transformational Theory. In J. Mezirow \& Associates (Eds.), Learning as Transformation: Critical Perspectives on a Theory in Progress (pp. 3-33). San Francisco, California: Jossey-Bass Inc.

Rabow, J., \& Yeghnazar, P. (2009). Transformative Teaching in the University: Uncovering and Confronting Racism, Sexism and Homophobia. Teaching Race and Ethnicity in Higher Education: Perspectives from North America. Birmingham: Center for the Study of Sociology, Anthropology, and Politics.

Taylor, E. W. (1997). Building upon the Theoretical Debate: A Critical Review of the Empirical Studies of Mezirow's Transformative Learning Theory. Adult Education Quarterly, 48, 34-59.

Taylor, E. W. (2007). An Update of Transformative Learning Theory: A Critical Review of the Empirical Research (1999-2005). International Journal of Lifelong Education, 26, 173-191. http://dx.doi.org/10.1080/02601370701219475 


\section{Appendix 1}

\section{Class event}

Nellie Wong's Poem

Blue Eyes/Brown Eyes Exercise

Dividing into LTD groups (just LTD groups)

Discussion on Pedagogy of the Oppressed by Paulo Freire

Stereotype Activity

Discussion on You Can't Say You Can't Play by Vivian Gussin Paley

Discussion on A Threat in the Air by Claude M. Steele

Marva Collins Video TITLE

LTD Discussions (Same as above??)

Discussion on Voices of Pain, Voices of Hope by Prof. Jerome Rabow

Discussion on We Can't Teach What We Don't Know by Gary R. Howard

Privilege Activity

Color of Fear video and class discussions on race

Discussion on "Unpacking the Invisible Knapsack” by Peggy McIntosh

Discussion on Lies My Teacher Told Me by James W. Loewen

Discussion on "Sexual Assault on Campus" by Elizabeth A. Armstrong, Laura Hamilton, and Brian Sweeney

Discussions on gender/gender role

\# of web posts

52

19

13

40

51

20

26

Discussion on "How Does It Feel to Be a Problem?” Article

Discussions on homosexuality $\quad 50$

Pink Triangle Experiment $\quad 29$

Gay Attitudes Survey

Scott Cozza/Boy Scouts Video

Inclusion/Exclusion Experiment $\quad 29$

Opposite Sex/Gender Roles Activity 34

Discussion on Letter from Birmingham Jail by Martin Luther King, Jr. 5

Discussion on A Race Is a Nice Thing to Have by Janet Helms 6

Jerome Rabow's class video $\quad 25$

$\begin{array}{ll}\text { Total web posts generated from class activities } & 781\end{array}$ 


\section{Appendix 2}

Mezirow’s Transformative Learning Steps as Applied to Students' Statements

1) A disorienting dilemma. (A person goes to a college for the first time in mid life and experiences a legitimate and vastly different worldview to his or her own and becomes disoriented about their own beliefs and life choices - a disorienting dilemma. For example, the main character in the movie Educating Rita from 1983.)

Student: The conversation we had after the exercise didn't make me feel better either. I had to sit there and listen to someone from the dominant group state how her parents had proposed investing in a home near UCLA so she could live in during her time at the university, but she had chosen not to accept and to work instead. While I do admire her for not taking the easy way out, I was just angry that some people have these privileges and I had to worry about having enough gas money to commute to school from East L.A. My parents couldn't afford a property near UCLA and we couldn't afford dorm rooms either. This exercise just showed me how much inequality there really was in this society, and even though I knew about it from articles, this experience made it more real to me.”

2) Self-examination with feelings of fear, anger, guilt or shame. (The implication of the new worldview generates feelings that stem from an uneasy, and at times frightening, consideration of previously ways of looking at the world that felt very certain.)

Student: During my time there (New Orleans), I was metaphorically thrown into a freezing cold pool of exposure. This stage has been described as guilt and shame-ridden. The white individual becomes aware of society's oppression of non-whites and adopts a great deal of guilt as a result. During my time down there, I recall one night after a day of particular revelatory research where I was so overcome by guilt that I sat on a curb for hours and cried.

3) A critical assessment of assumptions. (The person undertakes an assessment via critical reflection of some of their underlying basic beliefs as a consequence of the self-examination of the previous step. For example, a person may critically reflect on why he or she had not valued themselves and has missed opportunities in life because of that initial assumption about their place in the world.)

Student: I look back at my time down there and can now see the rush I was in to become everyone's savior that I encountered, as well as earn his or her acceptance. Luckily, taking this class a month after I returned from my trip and in the heart of my thesis writing neutralized my white-guilt motivations and led me towards a more levelheaded and sustainable projection of anti-racism.”

4) Recognition that one's discontent and the process of transformation are shared. (The person engages in rational discourse with friends, colleagues, family or fellow students and discovers that the new worldview is not foreign or weird to other people. They also discover that other people have had similar responses to learning in their lives and can understand the disruption of the disorienting dilemma.)

Student: Wow! I feel this way too, mainly because I was operating on all these assumptions that I could somehow "control" myself from getting assaulted. Now I think, holy shit, this can happen anywhere, at any time."

5) Exploration of options for new roles, relationships and actions. (Rational discourse is used to work through possible alternate ways to move forward in life with close friends, peers, teachers or colleagues.)

Student: I realize that women have way more to deal with them men do, and I hope we can learn from you. I hope the friends you have, both girls and guys, can be ones who look out for and respect each other. I think this will alleviate, hopefully, some of the fear that is felt.

6) Planning a course of action. (The person plans a way forward that will accord with their new larger, more flexible and developing worldview.)

Student: As evidence for how far I have come, I have recently begun openly discussing my sexual assault during intimate interviews for my music career. In the past, I would have been more inclined to keep my past private, however, I now see these interviews as incredible opportunities to raise awareness to an oppression that so often goes undiscussed. In the future I will be proud to continue sharing my story publically with the hopes that other women feel empowered and men feel more aware after hearing what I have to say.

7) Acquiring knowledge and skills for implementing one’s plan. (The person engages with different types of learning to gain specific knowledge and skills to follow their plan, such as training in new capabilities, or getting a new job.)

Student: I know many men; my self-included always want to fix problems. I want to discuss some suggestions 
that we can do to stop sexism and stop the threat of dominants. It is not a catchall list and we can’t fix every problem. Yet, I believe that it is possible to make a difference, even if it is a minor one. I feel like men should be aware of other people around them, what they are doing and what their motivations might be.

8) Provisional trying of new roles. (The person tries out their new roles in their life to see what happens, and to modify and adjust the roles as required, such as trying new work roles.)

Student: The night after class, I received a call from my neighbor at 1 am asking for a ride. I was already in bed at this point and told her that I couldn't. But then, I remember the discussion we had in class and I immediately called her back and offered the ride. Luckily she found one. The exercise has affected my actions in numerous ways and has changed the way I look at things now.

9) Building competence and self-confidence in new roles and relationships. (The person continues to practice their new roles with greater confidence and a wider range of situations such as trying a new job or continuing with new work in their existing job.)

Student: In May 2011, I was asked to perform with my band at Seattle Pride fest 2011, the largest open air and free gay rights music festival in the world. I enthusiastically accepted. This will be my very first music festival performance and I will be performing for over 70,000 attendees. I could not be more proud than to represent my alliance with support for gay rights within my professional career.

10) A reintegration into one's life on the basis of conditions dictated by one's new perspectives. (The person integrates the new responses to life, and the new skills and abilities with those they care about, in such a way as to be respectful of the newly-acquired expanded, and more flexible worldview.)

Student: Now that I am aware, I think that my advocacy role I will play will be to watch out for the sort of situation that takes advantage of women, sober or not, in addition to elevating my discourse and advocating for women when talking to whoever. 
Scientific Research Publishing (SCIRP) is one of the largest Open Access journal publishers. It is currently publishing more than 200 open access, online, peer-reviewed journals covering a wide range of academic disciplines. SCIRP serves the worldwide academic communities and contributes to the progress and application of science with its publication.

Other selected journals from SCIRP are listed as below. Submit your manuscript to us via either submit@scirp.org or Online Submission Portal.
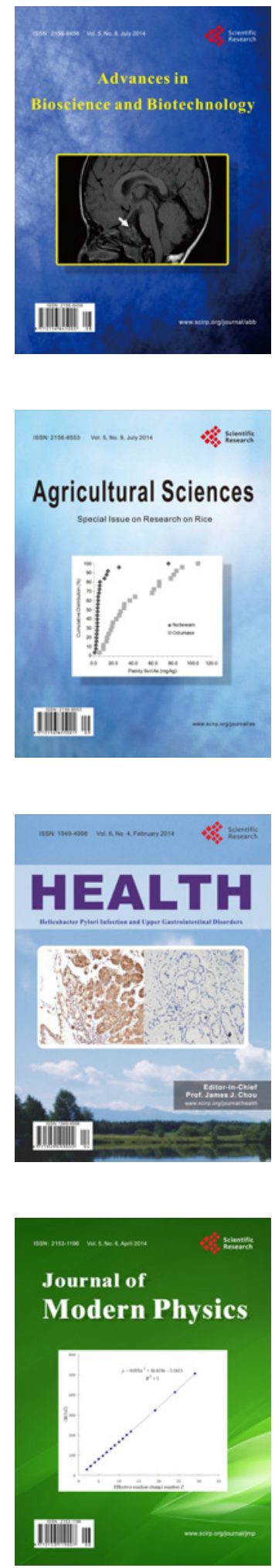
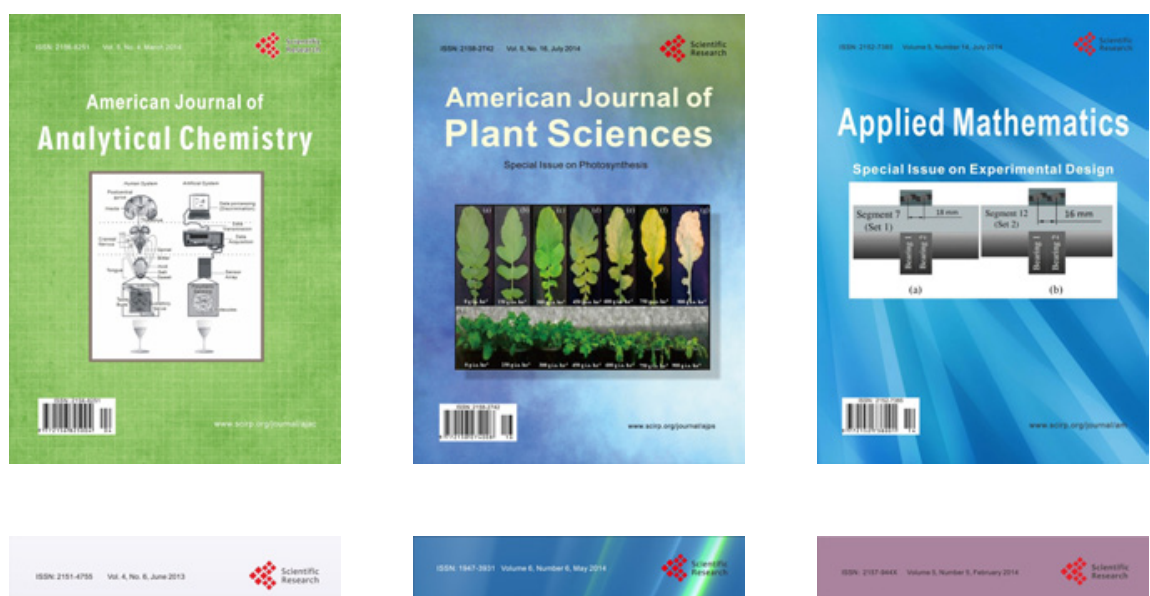

Creative Education
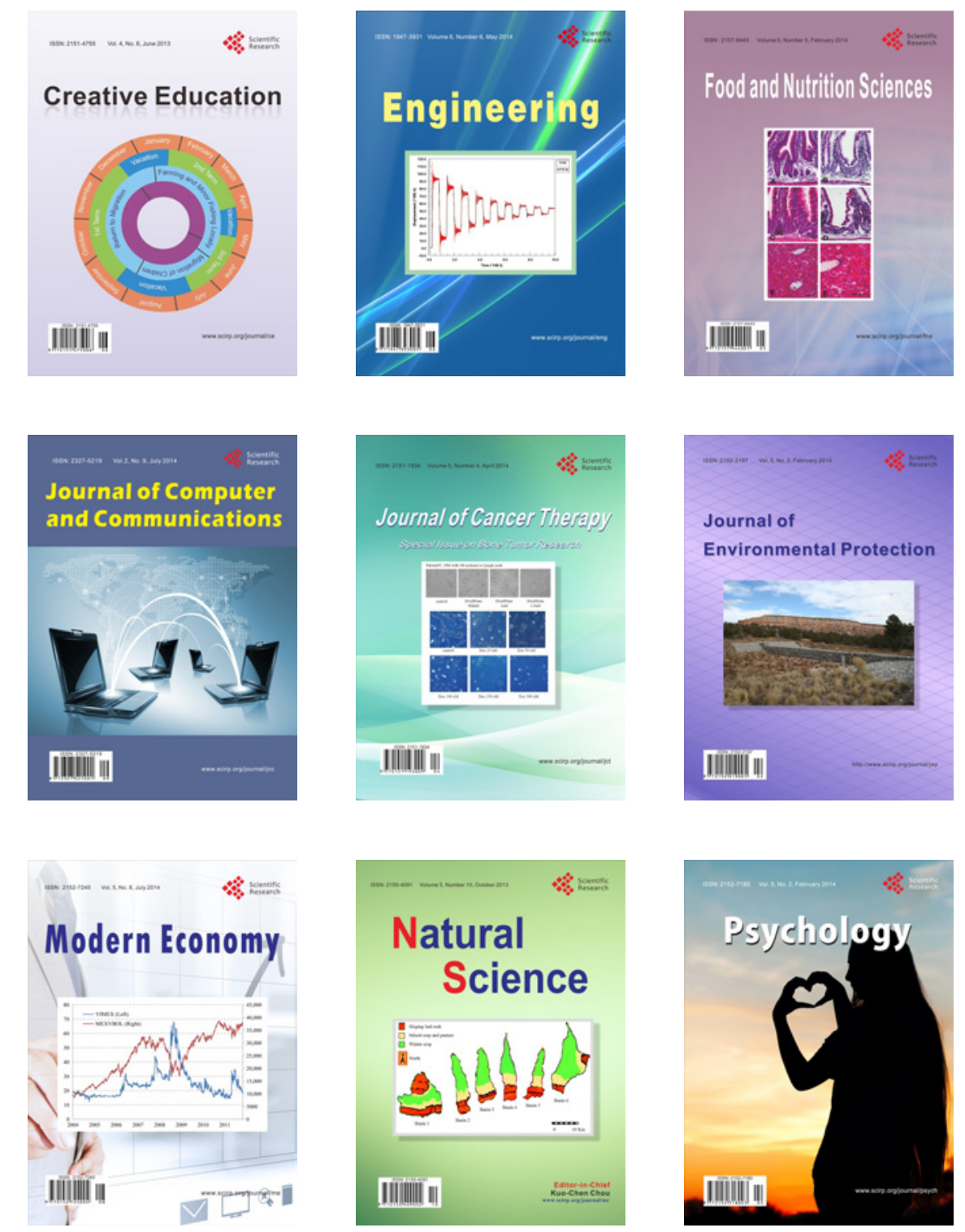